\title{
Usefulness of Transrectal Ultrasound for Predicting Carcinoma of Prostate
}

\author{
B. Vinodkumar ${ }^{1}$, Ravi Kumar Atluri² \\ ${ }^{1}$ Professor and HOD, ${ }^{2}$ Professor, Department of Radiology, Fathima Institute of Medical Sciences, Kadapa, Andhra Pradesh, \\ India
}

Corresponding author: Dr Ravi Kumar A, C-106, Elite Avenue, Mydukur Road, Near Reliance Petrol Bunk, Proddatur, Kadapa, AP - 516360, India

DOI: http://dx.doi.org/10.21276/ijcmsr.2019.4.3.43

How to cite this article: B. Vinodkumar, Ravi Kumar Atluri. Usefulness of transrectal ultrasound for predicting carcinoma of prostate. International Journal of Contemporary Medicine Surgery and Radiology. 2019;4(3):C196C199.

\section{A B S T R A C T}

Introduction: Incidence of prostatic carcinoma is increasing globally over the past few years and it is also on the rise in India. The enlarged prostate on TRUS shows variable features based on the pathology. In the present study we attempted to look at the usefulness of transrectal ultrasound (TRUS) to detect and to predict the presence of prostatic carcinoma. Study aimed to know the usefulness of transrectal ultrasound (TRUS) modality in predicting prostatic carcinoma.

Material and Methods: This was a prospective hospital based study in which 64 patients with enlarged prostate underwent transrectal ultrasound examination along with collection of trucut biopsy for tissue diagnosis. The sensitivity, specificity, positive predictive value and negative predictive value were calculated.

Results: The study group consisted of 64 patients with age ranging from 48 to 87 years. Carcinoma prostate was present in $35(54.6 \%)$ and $\mathrm{BPH}$ was present in 29 (45.3\%) cases respectively. The mean age for carcinoma and BPH were almost same, being 69.5 years and 68.4 years respectively. The sensitivity and specificity of TRUS to detect prostatic malignancy was $85.7 \%$ and $72.4 \%$ respectively. The positive predictive value and negative predictive value of TRUS to detect prostate malignancy was $78.9 \%$ and $80.7 \%$ respectively.

Conclusion: Carcinoma of the prostate is common in the sixth and seventh decades of life. Transrectal ultrasound is a useful modality to detect carcinoma of prostate and has a sensitivity of $85.7 \%$ with positive predictive value of almost $80 \%$. Mixed echogenicity or variable echogenic patterns on TRUS are more common in carcinoma than in BPH.

Keywords: Transrectal Ultrasound, Prostate Carcinoma, Sensitivity and Specificity of TRUS, PPV of TRUS

\section{INTRODUCTION}

Incidence of prostatic carcinoma is increasing globally over the past few years and it is also on the rise in India. ${ }^{1}$ Prostatic carcinoma is so common that it is the second most common cancer and also a common cause of cancer death worldwide. $^{2}$ The incidence of prostatic cancer is more in the western world as compared to India but recent trends show a rising incidence in our country as well. ${ }^{3}$ In all the suspected cases of prostatic cancer a three prong approach of digital rectal examination (DRE), serum PSA testing and biopsy of the prostate are to be performed. The final diagnosis is based on the histopathological findings on a trucut biopsy which is obtained by transrectal ultrasound guided biopsy. ${ }^{4}$

The enlarged prostate on TRUS shows variable features based on the pathology. In the present study we attempted to look at the usefulness of transrectal ultrasound (TRUS) to detect and to predict the presence of prostatic carcinoma.

Study aimed to know the usefulness of transrectal ultrasound (TRUS) modality in predicting prostatic carcinoma.

\section{MATERIAL AND METHODS}

This was a prospective hospital based study carried out in the department of Radiodiagnosis at Fathima Institute of medical Sciences, Kadapa, Andhra Pradesh over a period of two and half years. A total of 64 male patients were included in the study with age ranging from 48 to 87 years.

\section{Inclusion criteria}

1. Patients having features of lower urinary symptoms

2. Positive DRE findings of prostatomegaly

3. Patients with symptoms suggestive prostatic carcinoma

\section{Exclusion criteria}

1. Already known cases of prostatic carcinoma were excluded The TRUS procedure was carried out in the Ultrasound section of the department of Radiodiagnosis. The patient was put in the left lateral position and then a digital rectal examination was done to estimate the anal spinchter and rectal space. Then sufficient amount of lubricant was applied and the US probe was inserted gently. The prostate was assessed in the sagittal and transverse planes. The echogenicity of the gland, the volume of the gland, any parenchymal irregularities, 
intactness of the capsule were noted. Those patients who had abnormal DRE, or suspicious TRUS findings or elevated serum PSA levels were subjected to TRUS guided biopsy procedure. On an average, 6 to 12 core biopsies were taken and dropped into $10 \%$ neutral buffered formalin and the department of Pathology for histopathological processing of the tissue specimens. The patients in whom biopsy was done were given adequate antibiotic cover.

The pre-biopsy serum prostate specific antigen (PSA) levels were noted from the patients or from department of Biochemistry.

\section{RESULTS}

Most of the cases with enlarged prostate were seen in the 6079 years age group. The mean age for carcinoma of prostate 69.5 years and for $\mathrm{BPH}$ was 68.4 years (table-1).

Mixed echogenicity pattern was the most common pattern and was seen in $41(64 \%)$ cases.

Prostate gland outline irregularities on TRUS: The margin or outline irregularities were seen in 20/35 cases of carcinoma whereas 27/29 cases of BPH showed regular smooth outlines. In the two cases of $\mathrm{BPH}$ that showed irregularities there was a history of previous TURP procedures and recurrent urinary tract infections/prostatitis.

The mean prostate volume on TRUS: The mean volume of the prostate gland in malignancies was $81.5 \mathrm{~cm}^{3}$ with a range of 15.0 to $295 \mathrm{~cm}^{3}$.

Table 3 Ultrasound findings and Histopathology findings: Most of the mixed echogenicity pattern cases were diagnosed as adenocarcinoma on histopathology (table-3).

\section{Sensitivity and specificity of TRUS}

Sensitivity $=\mathrm{TP} / \mathrm{TP}+\mathrm{FN} * 100=30 / 38 * 100=85.7 \%$

Specificity $=\mathrm{TN} / \mathrm{TN}+\mathrm{FP} * 100=21 / 29 * 100=72.4 \%$

$\mathrm{PPV}=\mathrm{TP} / \mathrm{TP}+\mathrm{FP}^{*} 100=35 / 43 * 100=78.9 \%$

$\mathrm{NPV}=\mathrm{TN} / \mathrm{TN}+\mathrm{FN} * 100=29 / 34 * 100=80.7 \%$

Complications: Mild to moderate pain at the site of puncture was present in $42 / 64$ patients in the first three to four days

\begin{tabular}{|l|c|c|c|}
\hline Age (in years) & No. of cases (Carcinoma) & No. of cases (BPH) & Total no. of cases (\%) \\
\hline $40-49$ & - & 2 & $2(3.1 \%)$ \\
\hline $50-59$ & 2 & 8 & $10(15.6 \%)$ \\
\hline $60-69$ & 14 & 13 & $27(42.1 \%)$ \\
\hline $70-79$ & 15 & 3 & $18(28.1 \%)$ \\
\hline $80-89$ & 4 & 3 & $7(10.9 \%)$ \\
\hline Total & 35 & 29 & $64(100 \%)$ \\
\hline \multicolumn{2}{|r|}{ Table-1: Age-wise distribution of the patients with prostatomegaly } \\
\hline
\end{tabular}

\begin{tabular}{|l|l|c|c|}
\hline Variable & Ultrasound findings & No. of cases & Percent (\%) \\
\hline \multirow{4}{*}{ Echogenicity } & Mixed & 41 & $64 \%$ \\
\cline { 2 - 4 } & Isoechoic & 10 & $15.6 \%$ \\
\cline { 2 - 4 } & Hypoechoic & 8 & $12.5 \%$ \\
\cline { 2 - 4 } & Hyperechoic & 5 & $7.8 \%$ \\
\cline { 2 - 4 } & Total & 64 & $100 \%$ \\
\hline \multirow{3}{*}{ Ultrasound diagnosis } & BPH & 29 & $45.3 \%$ \\
\cline { 2 - 4 } & Carcinoma & $34.6 \%$ \\
\cline { 2 - 4 } & Total Table-2: Ultrasound findings & $100 \%$ \\
\hline
\end{tabular}

\begin{tabular}{|l|c|c|c|}
\hline Echogenicity & No. of cases & BPH & Carcinoma \\
\hline Mixed & 41 & 17 & 24 \\
\hline Isoechoic & 10 & 4 & 5 \\
\hline Hypoechoic & 8 & 3 & - \\
\hline Hyperechoic & 5 & 5 & 35 \\
\hline Total & 64 & 29 & \\
\hline \multicolumn{2}{|c|}{ Table-3: Ultrasound findings and Histopathology findings } \\
\hline
\end{tabular}

\begin{tabular}{|l|c|c|c|}
\hline & Biopsy positive & Biopsy negative & Total \\
\hline TRUS positive for malignancy & 30 & 8 & 38 \\
& TP & FP & 26 \\
\hline TRUS negative for malignancy & 5 & TN & 64 \\
\hline Total & FN & 29 & \\
\hline \multicolumn{2}{|c|}{ Table-4: Sensitivity and specificity of TRUS for carcinoma prostate } \\
\hline
\end{tabular}


as they came to collect the biopsy report and had urological consultation. Apart from pain, none of the patients had any major complication post-procedure that needed immediate surgical intervention.

\section{STATISTICAL ANALYSIS}

Statistical test of significane: chi square test; "p value": $<0.0001$ (significant). The sensitivity and specificity of TRUS to detect prostatic malignancy was $85.7 \%$ and $72.4 \%$ respectively. The positive predictive value and negative predictive value of TRUS to detect prostate malignancy was $78.9 \%$ and $80.7 \%$ respectively.

\section{DISCUSSION}

Transrectal ultrasound (TRUS) was initially used to evaluate rectal pathology only. Watanbe et $\mathrm{al}^{5}$ for the first time in 1967 obtained clinically applicable images of the prostate gland and since then TRUS has found its place in evaluating prostatic pathology.

In the current clinical practice, TRUS guided biopsies are preferred to manual biopsies. Manual biopsies based on digital palpation method have the disadvantage of missing localized pathologic lesions. ${ }^{6}$ In TRUS biopsies the biopsy needle can be visualized and are better as they pick up representative material. In TRUS guided biopsy specimens the rate of detection of malignancy is higher as compared to digitally guided biopsy. ${ }^{7}$ In our study all the biopsies were TRUS guided biopsies.

TRUS biopsy is considered the gold standard method to obtain representative biopsy material. However, in rare cases where the patients have a previous history of rectal amputation, a transperineal approach can be followed. ${ }^{8}$

It is recommended that for a gland volume of 30 to $40 \mathrm{ml}$, a minimum of eight cores should be sampled. For any first time testing, not more than 12 cores are to be sampled. ${ }^{9}$ A total of 18 cores can be collected for glands that are more than $55 \mathrm{ml}$ so as to increase the cancer detection rate. ${ }^{10}$ There is another technique called as Prostate saturation biopsy wherein, a total of 20 to 40 cores are collected but this technique is to be employed only when the initial biopsy comes negative in a patient in whom there is a very high index of suspicion for malignancy. This technique is time consuming for both the radiologist and the pathologist and also has higher rate of complications due to the increased number of punctures. ${ }^{11}$

The most recent prostate biopsy technique is a comprehensive 3-dimensional mapping biopsy (3DMB) technique that samples the entire gland. TRUS guided biopsies can be missed in almost $25-30 \%$ cases but in the 3DMB technique the risk of missing any cancer is minimal. ${ }^{12}$ Other newer technique is using an MRI-ultrasound fusion method to guide prostate biopsy. ${ }^{13}$

Age: In our study, the mean age of carcinoma of prostate was 69.5 years. This compares well with the findings of Hariharan et $\mathrm{al},{ }^{3}$ Korti et $\mathrm{al}^{14}$ and Ghagane et $\mathrm{al}^{15}$ who reported the mean age in their studies as above 65 years, 66 and 70 years respectively.

TRUS findings: The mean volume of prostate in malignant cases in our study was $81.5 \mathrm{~cm}^{3}$. Various authors have reported the mean prostatic size as $66.8 \mathrm{~g}$ and $58 \mathrm{ml}^{16,17}$ In our study, most of the carcinoma cases had mixed echogenicity pattern on ultrasound. Isiwele et $\mathrm{al}^{18}$ in their study observed $85 \%$ cases of carcinoma prostate to have mixed echogenicity on TRUS. In their study 'Mixed echogenicity' on TRUS correlated more with a histologic diagnosis of carcinoma prostate as $71.9 \%$ of their 32 patients with mixed echogenic features showed carcinoma on biopsy report. In our study, of the 41 cases with mixed echogenicity, 24 (59\%) showed carcinoma on the biopsy. In our study none of the hyperechoic lesions on TRUS were diagnosed as carcinomas on histopathology which is similar to the observation of Isiwele et al. ${ }^{18}$

We observed 5 cases with hypoechoic nodules, 4 of which were located in the peripheral areas. This is similar to the observations of Pinto et $\mathrm{al}^{19}$ who reported that hypoechoic nodules in the peripheral region have the highest predictive value in the detection of prostate cancer.

Hara et $\mathrm{l}^{8}$ in their study reported the specificity and sensitivity of suspicious nodules to be $88 \%$ and $31 \%$, respectively and the positive predictive value to detect prostatic carcinoma on TRUS as $74 \%$.

Complications: The common complications of TRUS guided biopsy are vasovagal attack, pain at the puncture site, hematuria, urinary tract infections, hematospermia and hematochezia in the first few days post-procedure. In our study, none of the patients had any major complication necessitating surgical intervention.

\section{CONCLUSION}

Carcinoma of the prostate is common in the sixth and seventh decades of life. Transrectal ultrasound is a useful modality to detect carcinoma of prostate and has a sensitivity of $85.7 \%$ with positive predictive value of almost $80 \%$. Mixed echogenicity or variable echogenic patterns on TRUS are more common in carcinoma than in $\mathrm{BPH}$. We conclude that TRUS is a simple and useful modality to detect prostatic malignancy and has the added benefit of collecting tissue by a guided biopsy.

\section{REFERENCES}

1. Majeed A, Babb P, Jones J, Quinn M. Trends in prostate cancer incidence, mortality and survival in England and Wales 1971-1998. BJU Int. 2000;85(9):1058-62.

2. Ferlay J, Shin HR, Bray F. International Agency for Research on Cancer; Lyon, France: 2010. GLOBOCAN 2008, Cancer Incidence and Mortality Worldwide: IARC Cancer Base No. 10.

3. Hariharan K, Padmanabha V. Demography and disease characteristics of prostate cancer in India. Indian J Urol. 2016;32(2):103-108.

4. Oranusi CK, Ugezu AI, Nwofor A. Diagnosis of prostate cancer with needle biopsy: Should all cases be biopsied before treatment? Niger J Clin Pract 2012;15(3):48-50.

5. Watanabe H, Igari D,Tanahasi Y, et al. Development and application of new equipment for transrectal ultrasonography. J Clin Ultrasound. 1974;2(4):91-98.

6. Carter BH, Partin AW. Diagnosis of prostate cancer. In: Walsh PC, Retik AB, Vaughan ED, Wein AJ editors. 
Campbell Urology. $7^{\text {th }}$ ed.; Philadelphia: WB Saunders; 1998. p. 2518-37.

7. Lippman HR, Ghiatas AA, Sarosdy MF. Systemic transrectal ultrasound guided prostate biopsy after negative digitally directed prostate biopsy. J Urol 1992;147(1):827-9.

8. Hara R, Jo Y, Fujii T, et al. Optimal approach for prostate cancer detection as initial biopsy: prospective randomized study comparing transperineal versus transrectal systematic 12-core biopsy. Urology 2008;71(6):191-5.

9. Jones JS, Patel A, Schoenfield L, et al. Saturation technique does not improve cancer detection as an initial prostate biopsy strategy. J Urol. 2006;175(3):485-8.

10. Scattoni $V$, Roscigno M, Raber M, et al. Initial extended transrectal prostate biopsy - are more prostate cancers detected with 18 cores than with 12 cores? J Urol. 2008;179(1):1327-31.

11. Stewart CS, Leibovich BC, Weaver AL, et al. Prostate cancer diagnosis using a saturation needle biopsy technique after previous negative sextant biopsies. J Urol. 2011;166(6):86-92.

12. Barqawi AB, Rove KO, Gholizadeh S, O'Donnell CI, Koul H, Crawford ED. The role of 3-dimensional mapping biopsy in decision making for treatment of apparent early stage prostate cancer. Journal of Urology 2011;18691(2):80-85.

13. Chen FK, de Castro Abreu AL, Palmer SL. Utility of Ultrasound in the Diagnosis, Treatment, and Followup of Prostate Cancer: State of the Art. The Journal of Nuclear Medicine 2016;57(10)(Suppl.3):13S-18S.

14. Korti PK, Prabhala S, Jayashankar E, Deshpande AK. Study of Transrectal Ultrasound Guided Biopsies of Prostate in Correlation with Serum Prostate Specific Antigen Level. IJPO 2017;4(1):604-610.

15. Ghagane S, Nerli R, Hiremath M, Wagh A, Magdum P. Incidence of prostate cancer at a single tertiary care center in North Karnataka. Indian J Cancer 2016;53(4):429-31.

16. Ahmed M, Maitama H, Bello A, Kalayi G, Mbibu $H$. Transrectal ultrasound findings in patients with advanced prostate cancer. Ann Niger Med.2010;4(2):59.

17. Eri L, Thomassen H, Brennhovd B, Haheim L. Accuracy and repeatability of prostate volume measurements by transrectal ultrasound. Prostate Cancer Prostatic Dis. 2002;5(1):273-8.

18. Isiwele EM, Ikpeme AA. Predictive Value of Transrectal Ultrasound in the Diagnosis of Prostate Cancer. International Journal of Contemporary Medicine Surgery and Radiology 2018;3(3):C66-69.

19. Pinto F, Totaro A, Palermo G, Calarco A, Sacco E, D'Addessi A, et al. Imaging in prostate cancer staging: Present role and future perspectives. Urol Int. 2012;88(2):125-36.

Source of Support: Nil; Conflict of Interest: None

Submitted: 06-08-2019; Accepted: 30-08-2019; Published online: 15-09-2019 